\title{
Implementing Investors in People: a case study from the NHS
}

\section{Introduction}

The National Health Service (NHS) is the largest employer in the UK and has a diverse workforce which comprises many different professional groups. This composition can make introducing a planned programme of change a complex and difficult task. This paper will examine the practice of introducing a change programme in the shape of Investors in People (IIP) within the public sector. In 1998 following a wide-ranging consultation with key stakeholders in the NHS including trade unions and professional bodies the UK government published a new Human Resource (HR) strategy for the NHS, Working Together: Securing a quality workforce for the NHS (Department of Health (DOH), 1998). A number of objectives and targets were set in the strategy including: developing comprehensive HR and organisational development action plans; introducing training and development plans for the majority of health professional staff; local policies on staff involvement; and conducting an annual staff attitude survey to help review the quality of working life. With such a wide reaching change agenda the implications for HR management and practices within the NHS is enormous. The IIP Standard can help to facilitate some of these changes and this article is concerned with the issues surrounding the practical implementation of introducing IIP within the NHS. The paper provides an overview of the Standard outlining progress within the NHS, a brief review of the literature on Investors in People and a description and analysis of how one NHS trust hospital successfully achieved the IIP Standard. It concludes by outlining 
some of the lessons learnt from introducing IIP in the NHS and the implications of the findings on future research and practice.

\section{The IIP Standard}

Investors in People is a national Standard which seeks to link training and development to business strategies in order to improve organisational performance. Aimed at organisations of all sizes, it was launched in Britain in October 1991 with the following national targets for IIP recognition:

$35 \%$ of organisations employing 50 or more by the year 2000 and $45 \%$ by 2002

a $70 \%$ of organisations employing 200 or more by the year 2000

The Standard is based on four key principles as shown in Table 1 and has 23 indicators related to key business areas such as communication, management roles and business planning, for example, “2.1 A written but flexible plan sets out the organisation's goals and targets". The process of becoming an Investor in People involves: diagnosing any gaps between current practice and the requirements of the Standard; making a commitment to IIP; communicating this commitment to all staff; planning and taking action to make necessary changes; recognition; and working towards continuous improvement. 
Principles Description

Commitment An Investor in People makes a commitment from the top to develop all employees to achieve its business objectives

Planning An Investor in People regularly reviews the needs, and plans the training and development of all employees

Action An Investor in People takes action to train and develop individuals on recruitment and throughout their employment

Evaluation An Investor in People evaluates the investment in training and development to assess achievement and improve future effectiveness

(source, IIP UK)

The Investors in People initiative is government funded and managed at a local level by the Training and Enterprise Councils/Chambers of Commerce Training and Enterprise (TECs/CCTEs), or LECs (Local Enterprise Companies) in Scotland. It is monitored under procedures controlled by Investors in People UK. The TECs/CCTEs are funded by central government and are given financial incentives for increasing the number of organisations committing to achieve IIP status and becoming recognised as achieving the IIP Standard. 
Investors in People UK are a non-departmental government body licensed by the Department for Education and Employment to promote and oversee the IIP Standard throughout the UK (Alberga et al., 1997; Taylor and Thackwray, 1995). In terms of NHS organisations committing to IIP there has been slow progress over the last few years. The figures from IIP UK for May 1999 for committed and recognised IIP organisations in the health and social work sector are 2353 committed and 1750 recognised organisations, which is a sector penetration rate of $36.8 \%$. The average penetration rate for IIP across all sectors is $32.9 \%$. In the NHS 181 organisations are recognised and 154 committed to IIP (source, IIP UK). These figures for the NHS relate to each record on the database, which means that one NHS organisation may have several records if the organisation is going for recognition department by department. A recent report into Investors in People and the NHS described the conversion from commitment to recognition as an Investor in People as poor, and considered this a sector failure (Parsons, 1995).

The literature on Investors in People is wide ranging from research commissioned by IIP UK examining good practice in HR and benchmarking this against the existing IIP Standard (Investors in People UK, 1994) to studies which offer mainly quantitative data from large scale surveys (Alberga et al., 1997; IRS, 1994). These studies have increased the understanding of the impact of IIP and give a good overview of the current trends and views from employers. Over the last few years literature has provided general advice and guidance on implementing the IIP Standard (McLuskey 1996; Taylor and Thackwray, 1995) however it does not offer any in depth analysis of the impact IIP has on organisations. A few qualitative studies do provide a more detailed analysis of the impact that IIP is having on UK organisations (Bennett et al., 1994; Rix et al., 1994). Despite the range of research into IIP it 
has been recognised that there is a limited amount of qualitative analytical and independent research into the impact of IIP (Down and Smith, 1998; Spilsbury et al., 1995). There has also been little rigorous study of IIP implementation (Joyce and Parkinson, 1998) with the accounts reporting on IIP within the NHS offering little description or critical analysis of practice (Barnett et al., 1998; Investors in People UK, 1997). This article attempts to redress the balance.

\section{Methodology}

The methodology adopted draws upon the author's experience of helping to manage a successful IIP project for a hospital trust. The report of the case study analyses the key events that took place between 1996 and 1998 from direct observation, surveys, discussion and documentary evidence. This evidence draws on the human resources and organisation development strategy, the IIP portfolio, the IIP external assessors report and the minutes from the IIP project team meetings (Internal Documents 1-4). A number of interviews were also conducted with IIP co-ordinators from other NHS health trusts that helped in developing the conclusions of the paper.

\section{Laying the foundations for IIP}

The NHS health trust that makes up this study is a combined acute, community and mental health hospital in the North of England with approximately 2,800 employees and a turnover of $£ 60$ million. It is geographically spread with a main hospital site, a set of laboratories offsite and a number of health centres throughout the district that it serves. The trust is a large 
and complex organisation offering a range of specialist services. It is organised into central management departments and clinical directorates, for example family health, medicine and surgery. All of the directorates are a business in their own right with a distinctive culture and management style with systems in place for staff appraisal and team briefings. IIP was seen as a framework for many of the initiatives undertaken and a process that would provide focus.

In 1995 a new chief executive was appointed to the trust and a review of the management of the organisation was carried out. The outcome was a range of measures which sought to change the philosophy, style and structure of the organisation. One such measure was the introduction of a devolved management system which allowed health care professionals, with general management support, make day to day decisions on the operation of the trust. The role of central management was to oversee strategic development and implementation, support and facilitate clinical activities and monitor the performance of individual directorates and the trust. A more informal organisational style was agreed with emphasis placed on cross-functional communication and effective planning by involving all the relevant parties. A cornerstone of the culture shift being sought was the concept of employee involvement with all employees becoming more responsible for their own learning and development, whilst receiving support from their line managers. The whole emphasis was on consolidating the realisation that the successful operation of the business was the shared responsibility of all staff not just a small number of managers. Issues such as involvement, self-directing and constructive feedback on organisation, team and individual performance were central to the change strategy. The chief executive and the senior management team recognised the value of the IIP process and committed the trust to achieving the IIP Standard. It was agreed that the trust should sign up for the whole organisation to become an Investor in 
People rather than a few directorates at a time there by ensuring equity across the organisation.

The IIP project team was established in May 1996 with 18 representatives from all departments and directorates within the trust. The team was made up mainly of middle managers and HR staff. There would be funding from the local TEC for IIP related initiatives and on-going publicity to keep the trust staff continuously informed of progress. The IIP project team was scheduled to meet at least once a month until the external assessment had taken place. The project team representatives were responsible for cascading information throughout their department or clinical directorate, which included keeping senior managers briefed on progress. Task groups were set up to deal with issues such as publicity and questionnaire analysis. A diagnostic questionnaire was distributed to trust staff with the questions based on the IIP Standard. The trust IIP project team received 1,311 completed questionnaires, which represented a response rate of $47 \%$. The responses could be broken down into a number of categories such as staff group, directorate and main working time. The results were analysed and following consultations with staff the trust and directorate IIP action plans were prepared and cascaded to all staff in the trust in December 1996. Monitoring of progress took place every month at the IIP project team meetings when each representative gave an update from their department or directorate. The IIP project benefited from the leadership of the chief executive as he chaired the project team and dealt with any problems surrounding the implementation of action plans within departments or directorates. 


\section{The assessment process}

The approach adopted to monitor progress against the trust wide and directorate IIP action plans was to train staff to conduct in-house assessments. In early 1997 fourteen members of the project team attended an internal assessor-training course recommended by the local TEC and facilitated by an experienced IIP external assessor. The IIP internal assessments were to take place in April and May 1997 with a rolling programme covering all parts of the organisation. The IIP project team agreed on a questionnaire to be used based on the 23 IIP indicators. The recommended sample size for the IIP interviews for an organisation with 2501-5000 employees was $2-4 \%$ but as this was to be the main internal assessment an overall sample size of $8-10 \%$ was agreed as the target figure. A cross section of staff from all departments and directorates were assessed with a total of 253 staff interviewed. As a result of the internal assessment the trust IIP action plan was revised and all departments were given a target of having five 'IIP building blocks' in place ready for the external assessment. These building blocks were the trust appraisal scheme, directorate or departmental training plans, structured local induction arrangements, evidence of evaluation of training and development activities over the short, medium and long term and awareness of business plans. The internal assessment also revealed good practice and was viewed by senior management as a success as it gave the trust five months to address any outstanding issues prior to the external assessment.

A portfolio task group was established to compile documentary evidence relating to the IIP indicators including the background of the organisation and details of recent organisational changes. Departments and directorates were encouraged to develop their own portfolios. The 
assessors were particularly interested in cultural issues, such as the general management style, staff participation and how directorates approached the management of change. As part of the preparation for the external assessment there were a number of awareness sessions for staff who had been selected for interview. For the staff being interviewed who could not attend the IIP awareness sessions a briefing pack was developed so that managers could inform staff in their own departments and directorates of how the external assessment process would work. Other developments that took place in the months leading up to the external assessment included a new trust induction course, the development of a staff handbook, the preparation of a training and development strategy and a set of guidelines on the evaluation of training and development activities. The external assessment took place over a two-week period in late 1997. A total of 176 staff were interviewed, which represented $6 \%$ of the workforce. A team of assessors carried out the interviews that were conducted on a one-toone and a group basis. The individuals selected for interview were a representative sample from all departments and directorates. The assessors used a number of audit trails, which ran from the highest grades to the lowest so that the effectiveness of communications could be verified, as well as the interface between managers and their staff. The assessors met staff on the wards and were presented with a portfolio of evidence from each directorate. In December 1997 the trust was informed that it had been successful in its bid and had been recognised as an Investor in People. The feedback from the IIP project team on the external assessment had raised a number of concerns. These ranged from the assessing team having difficulty in fully grasping the complexity of the trust's systems and processes to the appropriateness of the questioning techniques used by the assessors during the interviews. It was agreed to feed all these comments back to the external assessment team. In early 1998 the senior management of the trust decided to disband the IIP project team as it had 
successfully completed its mission. A trust wide group was established to take on the broader organisational development issues which were highlighted in the external assessment report. The need to embrace Investors in People as part of the wider human resources and organisation development strategy was regarded as important by the majority of the NHS trusts involved in this study.

\section{Conclusions}

Achieving the IIP award led to a number of benefits for the trust, for example achieving key aims of the trust business strategy and starting to change the culture as employees recognised the importance the trust placed on developing them in line with organisational objectives. The process the trust went through in achieving Investors in People status involved a range of staff across the whole organisation facilitating and motivating others to achieve the required standard. The IIP project team representatives took ownership of the IIP process and were able to get the key messages across to a cross section of employees from managers to front line staff. It was a development opportunity for most of the managers concerned to be involved with such a large corporate project headed by the chief executive. It reflected the change in management philosophy of operating a devolved management system with a culture of employee involvement and staff taking responsibility for their own learning and development.

The process the NHS trust went through to gain IIP status clearly reflected the importance that senior management attached to training and development as a contributor to organisational performance. The major concern in using the Investors in People initiative as a 
strategic tool for managing change is that it is a uniform process (Alberga et al., 1997) and one that does not have the flexibility to deal with a diverse workforce. The two areas that clearly demonstrate this from the case study were the lack of involvement of the medical staff in the IIP process and the limited impact that IIP had on key groups of the workforce. In the case of the medical staff they had no representation on the IIP project team and in many cases their only involvement was being interviewed as part of the external assessment. The only exceptions were the trust medical director and the clinical directors of each directorate who had key management roles to perform. The trust dealt with this issue by including a section in the trust IIP portfolio that described the links between performance assessment, training and development activity and business goals in respect of medical staff at the trust. The senior medical staff was acknowledged by the senior management of the trust as needing to be included within the IIP framework, especially in areas such as business planning and performance review. Performance appraisals for consultants was conducted through a process of informal peer review with unacceptable levels of performance resolved by peer pressure until performance improved or other appropriate action was taken. In terms of monitoring the training and development of the senior medical staff it had become custom and practice throughout the NHS for medical consultants to be entirely responsible for identifying, satisfying and evaluating their own training and development needs. These issues raise many questions about the links between the IIP indicators and medical staff, particularly in terms of their development and management roles. In the majority of cases the medical staff did not provide any evidence or input into the process of working towards the IIP Standard and omitting such an influential group of staff whilst still achieving the Standard is an area that clearly needs addressing. The second area of concern was the limited impact that IIP had on certain groups of health professionals. The IIP project team at the time of the internal 
assessments expressed concern that some managers with a broad span of control were finding it difficult to conduct performance appraisals and assess the training needs of all their staff. These were mainly community-based staff where one manager would typically be responsible for 30-40 staff. The sample selected for the external assessment excluded some large groups within the trust including community staff. The TEC advised that it was a matter for the assessing team to decide what was needed for them to conduct a satisfactory assessment and that it was normal practice for the assessors to only select some groups of staff as part of an audit trail approach.

Recent changes to the assessment process have resulted in a more customer focused approach and the assessor developing a better understanding of the culture of organisations through attending events and meetings (Investors in People UK, 1999). Whilst taking into account these changes this case study highlights gaps in the assessment process, challenges the increased perception of the Standard as a tool for managing change and raises the question of whether the IIP Standard is sophisticated enough to reach a diverse workforce. One possible solution could be offering employers with a diverse workforce additional indicators to aim for such as the management of diversity or the management of change.

The implications of the findings from this paper for managers and practitioners working in personnel and training are that achieving the IIP Standard can have clear benefits for the organisation as a planned programme of change. Problems may arise when there is an attempt to change the organisational culture faced with a diverse workforce made up of professional groups who wield a large amount of power and influence within the organisation. The message from the organisations which make up this study is that the IIP Standard should not 
be seen as a destination in its own right but that there needs to be recognition that IIP is part of a wider organisation development strategy which has to be built on. In order to substantiate the findings within this paper there needs to be further research into the impact of IIP on organisations with a diverse workforce. The changes to the external assessment process which have recently been introduced, once embedded, will also provide opportunities for research into the effectiveness of the assessment process and whether some of the gaps highlighted have been addressed. On a wider note further research could be carried out into the use of the IIP Standard as a tool for managing change in sectors outside the NHS. The outcome of the current strategic review of the IIP Standard (Arkin, 1999; IIP UK, 1999) and the impact the revised Standard has on organisations will undoubtedly lead to new research. Whatever approach is finally adopted needs to take into account the complexities of organisations with a diverse workforce.

\section{References}

Alberga, T., Tyson, S. and Parsons, D. (1997), “An evaluation of the Investors in People Standard", Human Resource Management Journal, Vol.7 No.2, pp.47-60.

Arkin, A., (1999), “Above and beyond”, People Management, Vol. 5 No.3, pp.40-41.

Barnett, S, and Richert, A. (1998), “Trustworthy”, People Management, Vol.4 No.11, pp.4647. 
Bennett, R.J., Wicks, P. and McCoshan, A. (1994), Local Empowerment and Business Services: Britain's Experiments with TECs, UCL Press, London.

Department of Health (1998), Working Together: Securing a quality workforce for the NHS, HMSO, London.

Down, S, and Smith, D. (1998), "It pays to be nice to people, Investors in People: the search for measurable benefits", Personnel Review, Vol. 27 No.2, pp.143-155.

Industrial Relations Services (1994), "Investors in People; an IRS survey of employers experience", Employee Development Bulletin, No.52, April.

Internal Document 1, Human Resources \& Organisation Development Strategy, confidential.

Internal Document 2, Investors in People Portfolio and Related Papers, confidential.

Internal Document 3, Investors in People Assessment Report, confidential.

Internal Document 4, Investors in People Project Team Minutes and Related Papers, confidential.

Investors in People UK (1994), Better People Better Business: An Introduction to Investors in People, Ref. IIP 63. 
Investors in People UK (1997), Wigan Leigh Health Services, Case Study.

Investors in People UK (1999), Practitioner, No.24, April.

McLuskey, M. S. (1996), Introducing Investors in People: a manager's guide and workbook, Kogan Page, London.

Parsons, D. (1995), Investors in People and the NHS: Overcoming the Sticking points, The HOST Consultancy, Horsham.

Rix, A., Parkinson, R. and Gaunt, R. (1994), Investors in People: a Qualitative Study of Employers, Employment Department, Sheffield.

Spilsbury, M., Moralee, J., Frost, D. and Hillage, J. (1995), Evaluation of Investors in People in England and Wales, Institute of Employment Studies.

Taylor, J. and Parkinson, S.T. (1998), “An assessment and analysis of Investors in People in Northern Ireland organisations", Total Quality Management, Vol.9 No.2-3, pp.345-356.

Taylor, P. and Thackwray, B. (1995), Investors in People Explained, Kogan Page, London. 